\title{
Growth of Micro-organisms in Gel-stabilized Two-dimensional Diffusion Gradient Systems
}

\author{
By JULIAN W. T. WIMPENNY* AND PAUL WATERS \\ Department of Microbiology. Unitersity College. Nen'port Road, Cardiff CF2 ITA, UK
}

(Receited 18 May 1984 ; revised 27 June 1984)

\begin{abstract}
The Szybalski wedge plate technique was modified to generate two-dimensional diffusion gradients for two environmental variables: $\mathrm{pH}$ value and $\mathrm{NaCl}$ concentration were selected in this study. After experimentation, $\mathrm{pH}$ values chosen ranged from 3.9 to 8.1 and salt concentrations from 23 to $79 \mathrm{~g} \mathrm{l}^{-1}$. The $\mathrm{pH}$ gradients were slightly sigmoidal whilst the salt gradients were approximately linear. The reproducibility of the technique was assessed and found to be satisfactory in replicate growth experiments. A wide range of growth patterns was observed for a large variety of different bacterial types. The growth boundary and the pattern details are sufficiently distinct to suggest that the technique can distinguish between closely related species or strains.
\end{abstract}

\section{INTRODUCTION}

Caldwell \& Hirsch (1973) and Caldwell et al. (1973) developed a steady-state twodimensional gradient plate, which they used successfully in a number of ecological experiments. Growth took place on a $2.5 \mathrm{~cm}$ square agar slab, which was fed from two sides at right angles to one another, with specific solutes from concentrated sources.

The Caldwell plate is complex and growth only takes place over a small area. This led us to develop two-dimensional plates having a larger area, using the wedge plate principle described for single dimensional systems by Szybalski (1952; see also Wimpenny et al., 1983, 1984). Twodimensional gradient plates have potential in a number of areas. These include taxonomy and systematics, where isolated organisms may be compared; in the investigation of community structure in ecology; in examining synergism between chemical effectors including biocides and antibiotics; in selecting strains for particular applications and in studying interactions between different species.

This communication describes the production of two-dimensional $\mathrm{NaCl}-\mathrm{pH}$ gradient plates, and discusses some initial results obtained using this system.

\section{METHODS}

Organisms and media. The following micro-organisms, all taken from the departmental culture collection, unless otherwise stated, were maintained on Tryptone Soy Agar (Difco) ( 40 g per litre of glass distilled water) at $4^{\circ} \mathrm{C}$ and subcultured in $200 \mathrm{ml}$ Nutrient Broth (Difco) (8 g per litre of glass distilled water) for use (names in inverted commas are not on the Approved Lists of Bacterial Names (Skerman et al., 1980)]: 'Achromobacter lacticum', Aeromonas sp., Arthrobacter sp. . Azotobacter cinelandii, Bacillus cereus NCTC 9947, Bacillus mycoides, Bacillus circulans, Bacillus licheniformis, Bacillus macerans, Bacillus meguterium NCTC 9521, Bacillus subtilis 'var. niger', Bacillus poly'myxa, Bacillus subtilis, Chromobacterium tiolactum, Corynbacterium equi, Corjnebacterium sp., Corynebacterium xerosis, Enterobacter cloacue, Escherichia coli K12, 'Flawobacternum arborescens', Klebsiella sp., Kurthia zopffi. Micrococcus luteus. Micrococius roseus, Proteus iulgaris, Pseudomonas aeruginosa 129, 'Serratia indica', 'Staphylococcus albus'. Staphylococcus aurews, Slaphylococcus suprophyticus, Streptococcus fueculis and Vibrio sp.

Plate preparation. Two-dimensional gradient plates were poured using an adaptation of the Szybalski wedge plate technique. (Szybalski, 1952: Szybalski \& Brysun, 1952). Salt and pH gradients were constructed at right angles to one another as follows. All plates were prepared in Sterilin wettable $100 \mathrm{~mm}$ square Petri dishes. Every 
plate consisted of four layers, each containing $15 \mathrm{ml}$ medium, which contained the following in $\mathrm{g}$ per litre of glass distilled water. Layer I contained Bacto-Agar (Difco), 25.0 and Nutrient Broth, 2.0. To $15 \mathrm{ml}$ of this medium was added $0.22 \mathrm{ml} 1 \mathrm{M}-\mathrm{H}_{2} \mathrm{SO}_{4}$. Layers 2 and 3 contained Bacto-Agar, 15.0 and Nutrient Broth, 2.0; layer 2 contained $0.44 \mathrm{ml} \mathrm{l} \mathrm{M-NaOH}$, whilst layer 3 contained $250 \mathrm{~g} \mathrm{NaCl} 1^{-1}$. Layer 4 consisted of $23.0 \mathrm{~g}$ Nutrient Agar I-1. All $^{-1}$ media were heated to boiling point before autoclaving at $121^{\circ} \mathrm{C}$ for $15 \mathrm{~min}$. $\mathrm{H}_{2} \mathrm{SO}_{4}$ and $\mathrm{NaOH}$ were added immediately before pouring each layer, since extremes of $\mathrm{pH}$ destroy the gelling properties of the agar during autoclaving. Once autoclaved, media were maintained at $70^{\circ} \mathrm{C}$ until poured. The high temperature made plate pouring easier, leading to more reliable gradients. All plates were poured on a levelling board in a laminar flow cabinet.

Pouring the plates. One edge of the plate was supported on a $3 \mathrm{~mm}$ diameter rod, when pouring layers 1 and 3. This allowed the medium to solidify as a wedge shape. Once the first layer had solidified and cooled, the plate was placed on a flat surface and layer 2 was poured. On cooling, the plate was turned through $90^{\circ}$, and one side again elevated by $3 \mathrm{~mm}$. The salt layer was then poured. Once solidified, the plate was placed on a flat surface, and the final layer poured. These plates were left for $24 \mathrm{~h}$, to allow the layers to equilibrate vertically by diffusion.

Inoculation. The inoculum was incubated at $30^{\circ} \mathrm{C}$ overnight on a rotary shaker. Then $1.0 \mathrm{ml}$ was added to $9 \mathrm{ml}$ sterile semi-solid Nutrient Broth medium, containing (in $\mathrm{g}$ per litre of glass distilled water) Nutrient Broth, 8.0 and Bacto-Agar, 2.0. After mixing, $1.0 \mathrm{ml}$ was removed and spread over the agar surface using an alcohol-flamed glass spreader. Once solidified, the plates were incubated at $30^{\circ} \mathrm{C}$ for up to a further $72 \mathrm{~h}$.

Mapping the results. Growth was mapped, with the aid of a grid etched at $5 \mathrm{~mm}$ intervals in both dimensions. The limits of growth were recorded as $x$ and $y$ co-ordinates. This information was plotted and recorded.

pH measurements. Surface pH was monitored at intervals using a glass needle electrode (MI-408B, Microelectrodes Inc., New Hampshire, USA) read against a standard calomel reference electrode. Results were recorded as $\mathrm{mV}$, on an Orion lonalyzer (model $801 /$ digital $\mathrm{pH}$ ), and converted to $\mathrm{pH}$ units using a calibration curve prepared from standard buffer solutions.

$\mathrm{NaCl}$ measurement. Salt concentrations were measured using a Type MCl (Mark IV) conductivity measuring bridge (Electronic Switchgear, London. UK). Samples were removed using a no. 4 cork borer and homogenized in $10 \mathrm{ml}$ distilled water, using 25 strokes of a glass homogenizer. This sample was placed in the measuring cell and a reading in $\mu \mathrm{S} \mathrm{cm}^{-1}$ recorded. A calibration curve was used to convert this to $\mathrm{NaCl}$ concentration. Using this method, media to which no $\mathrm{NaCl}$ had been added contained $1.0_{\mathrm{g} \mathrm{NaCl}}$ equivalent $1^{-1}$. Samples for $\mathrm{NaCl}$ determination were removed at $10 \mathrm{~mm}$ intervals across the plate.

\section{RESULTS}

\section{Choice of $\mathrm{pH}$ gradient}

Various plates were prepared containing different pH gradients (Fig. 1). A range of approximately $5 \mathrm{pH}$ units across the plate was deemed necessary. The sample which most closely met these requirements used the acid and alkali concentrations described in Methods (curve a).

\section{Gradient reproducibility}

Variations in $\mathrm{pH}$ and $\mathrm{NaCl}$ gradients were determined in replicate plates after storing them for $48 \mathrm{~h},\left(24 \mathrm{~h}\right.$ at room temperature and $24 \mathrm{~h}$ at $\left.30^{\circ} \mathrm{C}\right)$. Results for the $\mathrm{pH}$ gradient indicated a SEM of $\pm 0.17 \mathrm{pH}$ units in the alkaline region, rising to $\pm 0.54 \mathrm{pH}$ units at $\mathrm{pH} 6$, and falling once more to $\pm 0.10 \mathrm{pH}$ units where the agar was acidic (Fig. $2 a$ ). The salt gradient was more reproducible having an SEM of $\pm 1.0 \mathrm{~g} \mathrm{I}^{-1}$ over the whole plate (Fig. $2 b$ ).

\section{Time-dependent gradient changes}

Growth experiments took from 72 to $96 \mathrm{~h}$ after pouring the plates. During this period lateral diffusion took place. The extent of this diffusion was determined experimentally in uninoculated and inoculated plates. The results showed little change in the $\mathrm{pH}$ gradient for up to $96 \mathrm{~h}$ in uninoculated plates (Fig. $3 a$ ). Inoculation and growth led to significant pH changes. Typically, a $72 \mathrm{~h}$ culture of Bacillus cereus caused the $\mathrm{pH}$ values of the acidic region where growth took place to become more alkaline.

In contrast, there was a slight fall in the salt gradient over the $96 \mathrm{~h}$ period (Fig. $3 \mathrm{~b}$ ), but surface growth of organisms had no appreciable effect on the averaged values. 


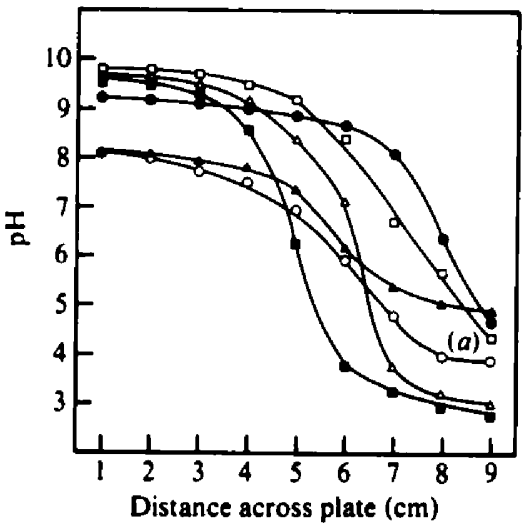

Fig. I. Selection of appropriate pH gradients. Acid and alkaline wedges were prepared with the following additions: $\mathrm{O}, 0.22 \mathrm{ml} 1 \mathrm{M}_{-} \mathrm{H}_{2} \mathrm{SO}_{4}+0.44 \mathrm{ml} 1 \mathrm{M}-\mathrm{NaOH}$ (standard system, curve a);, $0.22 \mathrm{ml} 1 \mathrm{M}$ $\mathrm{H}_{2} \mathrm{SO}_{4}+0.50 \mathrm{ml} 2 \mathrm{M}-\mathrm{NaOH} ; \square, 0.50 \mathrm{ml} 0.5 \mathrm{M}_{-} \mathrm{H}_{2} \mathrm{SO}_{4}+0.75 \mathrm{ml} 1 \mathrm{M}-\mathrm{NaOH} ; \square, 1.00 \mathrm{ml} 0.5 \mathrm{M}_{-} \mathrm{H}_{2} \mathrm{SO}_{4}$

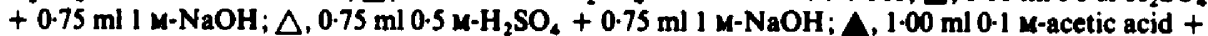
$2.0 \mathrm{ml} \mathrm{0.1} \mathrm{M-NH} \mathrm{NH}_{4} \mathrm{OH}$.

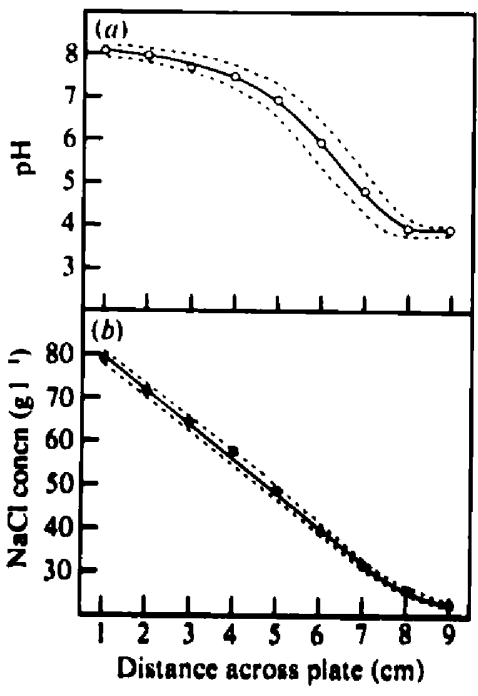

Fig. 2

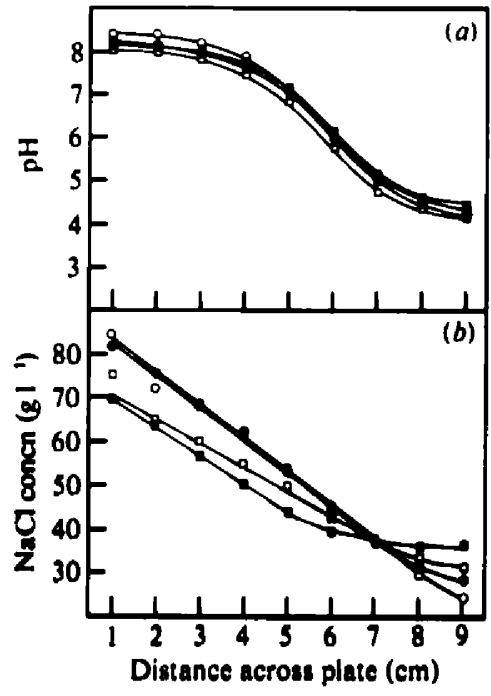

Fig. 3

Fig. 2. $\mathrm{pH}(a)$ and $\mathrm{NaCl}(b)$ gradients across each dimension of the two-dimensional diffusion gradient plate. Confidence limits are shown as broken lines.

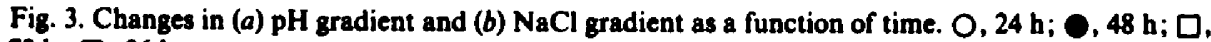
$72 \mathrm{~h} ; 0,96 \mathrm{~h}$.

\section{Mapping the growth zone}

Reproducibility. Replicate agar plates were prepared and inoculated as described in Methods, to determine variations in the position of the growth boundary, using different organisms. Each plate was inoculated $24 \mathrm{~h}$ after preparation, and incubated for a further $\mathbf{4 8} \mathrm{h}$. Growth on each plate was then mapped, and the mean and SEM values were calculated for each species (Fig. $4 a-$ d).

Salt tolerance for Bacillus cereus 9947 increased gradually from $23 \mathrm{~g} \mathrm{l}^{-1}$ at $\mathrm{pH} 4.1$ to $49 \mathrm{~g} \mathrm{I}^{-1}$ from pH 7.5 to 8.1 (Fig. 4a). Salt tolerance for 'Flavobacterium arborescens' was maintained at $49 \mathrm{~g} \mathrm{l}^{-1}$ over the $\mathrm{pH}$ range 6 to $8 \cdot 1$. Lower $\mathrm{pH}$ values decreased its tolerance, and below pH $5 \cdot 0$ 


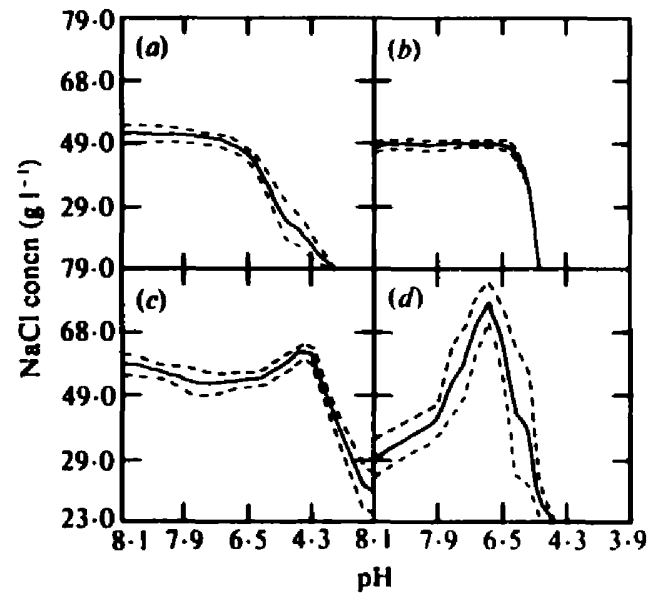

Fig. 4

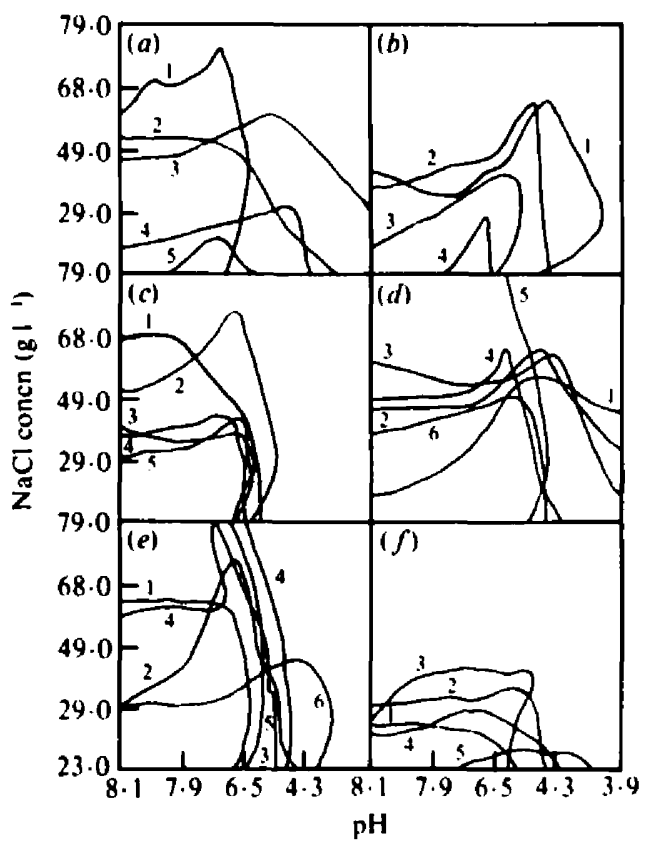

Fig. 5

Fig. 4. Growth of micro-organisms on $\mathrm{pH}-\mathrm{NaCl}$ two-dimensional gradient plates. Broken lines indicate the confidence limits for five samples. (a) Bacillus cereus, (b) 'Flaibbacterium arborescens'. (c) 'Serratia indica', (d) 'Staphylococcus albus'.

Fig. S. Growth patterns observed with difierent organisms. (a) Bacillus species: $1, B$. licheniformis: $2, B$. cereus; 3, B. megaterium; 4, B. macerans; S, B. mycoides. (b) Bacillus species: $1, B$. subtilis; 2 , B. subtilis 'var. niger': 3, B. circulans; 4, B. polymyxa. (C) Coryneform organisms: 1, Corynebacterium sp. ; 2 , Corynebacterium xerosis; 3, Corynebacterium equi; 4, Kurthia zopfii: 5, Arthrobacter sp. (d) Gramnegative organisms: 1, Escherichia coli KI2; 2, Enterobacter cloacae; 3, 'Serratia indica'; 4, Proteus vulgaris; 5, Klebsiella sp.; 6. Pseudomonas aeruginosa. (e) Gram-positive cocci: 1, Streptococcus faecalis: 2, 'Staphylococcus albus'; 3, Staph. aureus; 4, Staph. saprophyticus; 5, Micrococcus luteus; 6, M. roseus. ( $f$ Miscellaneous bacteria: 1, Azotobacter vinelandii; 2 . 'Achromobacterium lacticum': 3, Vibrio sp.; 4. Aeromonas sp.; 5, Chromobacterium violaceum.

there was no growth at all (Fig. 4 b). 'Serratia indica' (Fig. $4 c$ ) had a high salt tolerance $\left(58 \mathrm{~g}^{-1}\right.$ ) from $\mathrm{pH} 4.3$ to $8 \cdot 1$. Lower $\mathrm{pH}$ values led to a fall in salt tolerance, although at low salt concentrations the organism could grow over the entire test range (pH 3.9-8.1). 'Staphylococcus albus' (Fig. 4d) showed high salt tolerance $\left(77.5 \mathrm{~g}^{-1}\right)$ at $\mathrm{pH}$ values near 6.8 . No growth was recorded at $\mathrm{pH}$ values below 4.7, whilst at $\mathrm{pH} 8.1$ the salt tolerance was reduced to $29 \mathrm{~g}^{-1}$.

Some results using a range of different bacteria. A wide range of bacterial species were examined using the salt-pH gradient plates set up as described in Methods. All the species examined grew at some position in the system; however, organisms like Chromobacterium violaceum appeared near the extreme edge of the system, at the lowest salt concentrations. Some species showed considerable salt tolerance, in particular the Gram-positive cocci such as 'Staphylococcus albus' and S. aureus.

Specific groups of organisms are collected together in Fig. 5. Nine different species of bacilli were examined and showed a high degree of variation in their tolerance both to salt and to $\mathrm{pH}$ gradients. Bacillus polymyxa, for example, is sensitive to both factors, showing only slight salt tolerance near neutral pH values. On the other hand, several of the bacilli showed a broad range of tolerance to both $\mathrm{pH}$ and salt concentration. These included $B$. megaterium, $B$. subtilis and $B$. licheniformis, though the latter was quite sensitive to acid $\mathrm{pH}$ values.

The coryneform organisms examined were much more uniform in their behaviour. Thus they generally showed less of a characteristic 'horn' extending into the high salt zone at neutral pH 
values, which was a common feature for many other species. They seemed uniformly sensitive to acidic $\mathrm{pH}$ values less than about $\mathbf{p H} 6 \cdot 2$.

Gram-negative rod shaped bacteria are represented in Fig. $5(d)$. The Klebsiella sp. was tolerant to high salt concentrations at alkaline $\mathrm{pH}$ values. 'Serratia indica', Enterobacter cloacae and $E$. coli $\mathrm{K} 12$ were able to grow at all $\mathrm{pH}$ values.

A miscellaneous group of Gram-negative bacteria all showed considerable sensitivity to salt. Of these, Chromobacterium violaceum was the most sensitive. Whilst Azotobacter vinelandii is almost as sensitive, the relative pH sensitivity of the two organisms means that their habitat domains scarcely overlap.

The Gram-positive cocci (Fig. 5e.) showed the greatest salt tolerance of any group, and several species, especially the staphylococci, could grow at the highest salt concentrations present on the plate. What was most interesting was the 'horn' which was most marked with ' $S$. albus' and $S$. saprophyticus. Here salt sensitivity was totally dependent on $\mathrm{pH}$ value.

\section{Discussion}

Two-dimensional gradient plates generate a smooth continuum of solute concentrations so that, between limits, every concentration of one factor is matched against all concentrations of a second. Growth on such a system generates a pattern which seems in general to be unique for specific organisms.

Salt and $\mathrm{pH}$, the factors selected in these experiments, are two of the most important environmental variables, and as the results demonstrate, are capable of discriminating between different species. The Szybalski wedge plate technique, originally developed for onedimensional gradients only, proved the most convenient method for constructing twodimensional gradient plates.

The salt gradient was almost linear and showed only small variations in replicate experiments. The $\mathrm{pH}$ gradient was sigmoid, as might be expected; however, it should be possible to straighten this using a mixture of different $\mathrm{pH}$ buffers in the medium. This was not attempted in the interests of simplicity. pH gradients were relatively stable over the periods chosen; whilst they proved more repeatable at extreme $\mathrm{pH}$ values, they were less so around neutrality.

Growth patterns could be replicated reliably in four different test species. In addition to the close similarity of the gross profile, the substructure of the growth as a whole could often give additional information on the species identity. This was particularly true in older cultures, where changes in the gradients led to slight secondary growth, sometimes appearing as bands or bars.

A common phenomenon in the majority of species tested was the marked salt tolerance shown at near neutral $\mathrm{pH}$ values. Since most bacteria were more sensitive to acid than to alkaline $\mathrm{pH}$ values, the resultant growth often assumed a horn-like shape extending into the higher salt concentrations. An explanation for this phenomenon is not readily apparent, since these experiments do not themselves distinguish between effects due to $\mathrm{NaCl}$, or effects connected with lower water activity and higher osmotic pressures. Experiments where $\mathrm{KCl}$ replaced $\mathrm{NaCl}$ gave similar results, suggesting that the effects were not purely chemical.

The gradient plates, in contrast to the system developed by Caldwell $e t$ al. (1973) were not steady-state systems. We have used steel or plastic cutters inserted into the agar to prevent diffusion after the plates were inoculated (Wimpenny, 1981 ; J. W. T. Wimpenny \& P. Waters, unpublished observations); however, experience suggests that the gradients are stable enough to obtain repeatable patterns without recourse to this step.

The two-dimensional gradient plate allows the production of a complete map of the responses of one or more organisms to two environmental variables. A further dimension could be added to give a third variable. For example, a series of ten two-dimensional plates could be incubated at ten different temperatures. Alternatively, each of ten different plates could contain a different uniform concentration of a third solute. The two-dimensional maps generated from each plate could then be stacked to generate a three-dimensional object in space which should be characteristic for a particular species or strain. In practice, micro-organisms respond to many more than three environmental variables. It is impossible to represent these multi-dimensional 
domains in the real world. They do have theoretical value in endeavouring to understand activity and habitat parameters in ecology. This has been discussed more fully by Hutchinson $(1957,1965)$. It is clear that there are mathematical techniques using computer graphics which can interpret problems of multi-dimensionality. This area is currently being explored.

It is a pleasure to acknowledge the contributions of A. Peters, who tested early versions of the two-dimensional gradient plate, during his Honours research project.

\section{REFERENCES}

Caldwell, D. E. HiRsch, P. (1973). Growth of microorganisms in two-dimensional steady-state diffusion gradients. Canadian Joumal of Microbiology 19, 53-58.

Caldwell, D. E., Lai, S. H. \& Tiedie, J. M. (1973). A two-dimensional steady-state diffusion gradient for ecological studies. Bulletin of Ecology Research Communication (Stockholm) 17, 151-158.

Hutchinson, G. E. (1957). A Treatise on Limnology 1. New York: John Wiley.

Hutchinson, G. E. (1965). The Ecological Theater and the Evolutionary Play, pp. 26-78. Newhaven: Yale University Press.

SKERMaN, V. B. D., MCGowaN, V. \& SNeath, P. H. A. (1980). Approved lists of bacterial names. International Journal of Systematic Bacteriology 30, 225-420.

SzyanLsxi, W. (1952). Gradient plates for the study of microbial resistance to antibiotics. Bacteriological Proceedings, 36.
SzYanlaxt, W. \& BRYson, V. (1952). Genetic studies on microbial cross resistance to toxic agents. I. Cross resistance of Escherichia coli to fifteen antibiotics. Journal of Bacteriology 64, 489-499.

WMPENNY, J. W. T. (1981). Spatial order in microbial ecosystems. Biological Reviews 56, 295-342.

WMPenNy, J. W. T., Lovit, R. W. C CoOMBs, J. P. (1983). Laboratory model systems for the investigation of spatially and temporally organised microbial ecosystems. Symposia of the Society for General Microbiology 34, 67-117.

WIMPENNY, J. W. T., CoOMEs, J. P. \& LovitT, R. W. (1984). Growth and interactions of microorganisms in spatially heterogeneous ecosystems. In Current Perspectives in Microbial Ecology, pp. 291-299. Edited by M. J. Klug \& C. A. Reddy. Washington, DC: American Society for Microbiology. 